\title{
Orientation of rapid thermally annealed lead zirconate titanate thin films on (111) Pt substrates
}

Keith G. Brooks, Ian M. Reaney, Radosveta Klissurska, Y. Huang, L. Bursill, ,) and N. Setter

Département de Materiaux, Laboratoire de Céramique, Ecole Polytechnique Fédérale de Lausanne, Lausanne, CH-1015, Switzerland

(Received 8 December 1993; accepted 21 June 1994)

\begin{abstract}
The nucleation, growth, and orientation of lead zirconate titanate thin films prepared from organometallic precursor solutions by spin coating on (111) oriented platinum substrates and crystallized by rapid thermal annealing was investigated. The effects of pyrolysis temperature, post-pyrolysis thermal treatments, and excess lead addition are reported. The use of post-pyrolysis oxygen anneals at temperatures in the regime of $350-450{ }^{\circ} \mathrm{C}$ was found to strongly affect the kinetics of subsequent amorphous-pyrochlore-perovskite crystallization by rapid thermal annealing. The use of such post-pyrolysis anneals allowed films of reproducible microstructure and textures [both (100) and (111)] to be prepared by rapid thermal annealing. It is proposed that such anneals and pyrolysis temperature affect the oxygen concentration/average $\mathrm{Pb}$ valence in the amorphous films prior to annealing. Such changes in the $\mathrm{Pb}$ valence state then affect the stability of the transient pyrochlore phase and thus the kinetics of perovskite crystallization.
\end{abstract}

\section{INTRODUCTION}

The crystallization of and, hence, resultant microstructure, texture, and ferroelectric properties of lead zirconate titanate (PZT) thin films are known to depend upon numerous parameters. ${ }^{1,2}$ Published techniques for the synthesis of PZT thin films can be divided into two categories: those that use in situ crystallization (i.e., crystallization during deposition) and those that involve post-deposition crystallization of a pre-existing amorphous layer. MOCVD and physical deposition at elevated temperatures fall into the former category. 3,4 For in situ crystallization, $\mathrm{O}_{2}$ partial pressure is known to be a critical process control parameter.

The second category includes most chemical and low temperature physical deposition techniques. Fox and Krupanidhi ${ }^{5}$ demonstrated that the oxygen content of as-sputtered lead lanthanum titanate films had a profound effect on the transformation to perovskite during subsequent annealing. Oxygen deficient films fully transformed to perovskite, whereas pyrochlore formed when an excess of oxygen was present. This was shown to be related to $\mathrm{Pb}$ valence state, and independent of $\mathrm{Pb}$ content. ${ }^{5}$ The effects of annealing atmosphere (i.e., $P_{\mathrm{O}_{2}}$ ) on perovskite crystallization from an amorphous phase have also been reported. Other thermal treatments, pre- and post-crystallization, are known to influence the nucleation, microstructure, texture, and electrical properties of PZT films. ${ }^{2}$ An investigation of the critical

\footnotetext{
a) On leave from School of Physics, The University of Melbourne, Parkville, 3052, Victoria, Australia.
}

parameters for post-deposition crystallization of amorphous films derived from spin casting of sol-gel solutions is presented below.

The chemical and thermal stability, crystallographic structure, and quality of the substrate material(s) also play key roles in the preparation of high quality PZT thin films. ${ }^{1,2,6,7}$ The most frequently reported substrate material system to date is $\mathrm{Pt} / \mathrm{Ti} / \mathrm{SiO}_{2} / \mathrm{Si}$. The deposition conditions and post-deposition annealing of the Pt are known to affect its microstructure, density, and orientation. $^{7,8}$ The degree of orientation of the Pt affects the microstructure of the PZT thin films deposited on it.

Other factors for which an effect on the crystallization behavior of perovskite thin films has been reported include thermal processing parameters (temperature, heating rates, time, and atmosphere), ${ }^{1,6,9-11}$ film stoichiometry or more specifically $\mathrm{Pb}$ content, ${ }^{1,6,11-13}$ and dopant additions. ${ }^{12,14-16}$

Considering the specific case of films prepared by the chemical techniques of sol-gel and MOD, other parameters are also significant. Film synthesis is sensitive to the precursors used (solubility, reactivity, and molecular weight), ${ }^{17-19}$ the conditions of prehydrolysis and condensation in the case of sol-gel processes (acid or base catalysis), ${ }^{19-21}$ and combustion characteristics of the precursor material (thermal stability and organic content) during pyrolysis. These factors impact on the nanoscale homogeneity of the amorphous film prior to crystallization.

In previous work, we have observed that PZT films of random orientation, or strong (111) or (100) textures could be prepared on $\mathrm{Ti} / \mathrm{Pt}$ bilayer metallizations by 
rapid thermal annealing (RTA) ${ }^{6}$ Previous transmission electron microscopy (TEM) investigations of the crystallization of free-standing sol-gel-derived PZT films on Pt TEM grids showed that the $P_{\mathrm{O}_{2}}$ and heating rate during the annealing process strongly affected the crystallization temperature and resultant phases obtained (perovskite and pyrochlore). ${ }^{22}$ In this study, we have investigated the critical parameters controlling the nucleation, growth, and subsequent microstructure of PZT films prepared by sol-gel processing on $\mathrm{Pt} / \mathrm{Ti} / \mathrm{SiO}_{2} / \mathrm{Si}$ substrates.

Specifically, the effects of pyrolysis temperature, low temperature $\left(<450{ }^{\circ} \mathrm{C}\right)$ post-pyrolysis treatments in various atmospheres, and $\mathrm{Pb}$ stoichiometry were investigated. Emphasis was placed on controlling the oxygen concentration in the films prior to rapid thermal annealing. PZT films were prepared by a sol-gel process based on methoxyethanol solvent first described by Budd et al. ${ }^{23}$

It is demonstrated that low temperature $\left(<450{ }^{\circ} \mathrm{C}\right)$ thermal treatments prior to crystallization by RTA strongly impact on the perovskite crystallization kinetics. The oxygen concentration in the amorphous films prior to annealing is shown to be one of the most important control parameters in order to prepare films of reproducible texture and microstructure by rapid thermal annealing.

\section{EXPERIMENTAL}

A modified sol-gel process was used to prepare $\mathrm{Pb}_{1+x}\left(\mathrm{Zr}_{0.53} \mathrm{Ti}_{0.47}\right) \mathrm{O}_{3}$ precursor solutions, with $x$ varying between 0 and 0.1. The organometallic precursors included: $\mathrm{Pb}\left(\mathrm{C}_{2} \mathrm{H}_{3} \mathrm{O}_{2}\right)_{2} \cdot 3 \mathrm{H}_{2} \mathrm{O}, \mathrm{Zr}\left(\mathrm{OCH}_{2} \mathrm{CH}_{2} \mathrm{CH}_{3}\right)_{4}$, and $\mathrm{Ti}\left(\mathrm{OCH}_{2} \mathrm{CH}_{2} \mathrm{CH}_{3}\right)_{4}$. Details of the precursor solution synthesis have been previously reported. ${ }^{6}$ For the typical case, no hydrolyzing agents were added to the precursor solution.

Silicon substrates with deposited $\mathrm{SiO}_{2} / \mathrm{Ti} / \mathrm{Pt}$ layers of thickness 1000,10 , and $100 \mathrm{~nm}$, respectively, obtained from a commercial source (Thomson TCS, Saint Egreve Cedex, France) were used throughout the study. PZT films were prepared by a multiple layer spincoating method. A filtered $0.4 \mathrm{M}$ precursor solution was applied to the substrate by spin coating at $3000 \mathrm{rpm}$ for $30 \mathrm{~s}$. The resulting film was immediately pyrolyzed by placing on a digitally controlled hot-plate in air for $15 \mathrm{~s}$, followed by rapid cooling to ambient temperature. Pyrolysis temperatures between 350 and $450{ }^{\circ} \mathrm{C}$ were investigated. Films of desired thickness were obtained by repetition of this process. Typically, five layers yielded a film $0.26-0.28 \mu \mathrm{m}$ thick after crystallization. In some cases a post-pyrolysis thermal treatment at temperatures in the range of 300 to $450{ }^{\circ} \mathrm{C}$ was employed. Atmospheres ranging from oxidizing $\left(\mathrm{O}_{2}\right)$ to reducing
(Ar or $\mathrm{N}_{2} / \mathrm{H}_{2}: 92 / 8$ ) were employed for these thermal treatments.

Annealing conditions for PZT crystallization were varied within the following ranges: $500-700{ }^{\circ} \mathrm{C}$ in air or $\mathrm{O}_{2}$ at a rate of $80{ }^{\circ} \mathrm{C} / \mathrm{s}$, holding at the desired temperature for $1 \mathrm{~s}$ to $1 \mathrm{~h}$. A "typical" annealing condition consisted of heating at $80^{\circ} \mathrm{C} / \mathrm{s}$ to $600{ }^{\circ} \mathrm{C}$ and holding for $1 \mathrm{~min}$, followed by rapid cooling.

For the case of randomly oriented films, some of the preparation parameters were modified. Prior to film preparation, the sol solution was prehydrolyzed by the addition of $\mathrm{H}_{2} \mathrm{O}$ and $\mathrm{HNO}_{3}$ in the molar ratio $2: 1: 2$, $\mathrm{H}_{2} \mathrm{O}: \mathrm{HNO}_{3}: \mathrm{PZT}$. The catalysts were diluted with 2-methoxyethanol prior to admixing with the PZT precursor solution. The pyrolysis step was also modified to obtain the randomly oriented films. Between successive layers, the films were dried at $250{ }^{\circ} \mathrm{C}$, with pyrolysis being completed during subsequent rapid thermal annealing.

$\mathrm{PbO}_{x}$ films were prepared to investigate the reactions between $\mathrm{PbO}_{x}$ and the platinum substrate, based on published work indicating the formation of $\mathrm{PbPt}_{x}$ and attributing said formation to the development of (111) textured PZT films. ${ }^{9}$ Films were prepared by using a solution preparation technique analogous to that employed for PZT. Pyrolysis temperatures in the range of 300 to $400{ }^{\circ} \mathrm{C}$ were investigated.

Films were analyzed by x-ray diffraction (XRD) at various stages of preparation. Analysis consisted of standard $\theta-2 \theta$ coupled x-ray diffraction using $\mathrm{Cu} \mathrm{K}_{\alpha}$ radiation with a Siemens diffractometer. The range of angles scanned and step count times were varied depending on the purpose of the particular analysis.

TEM analyses, both in transverse section and plan section were carried out on selected samples using either a Philips Model EM430 or CM20 microscope. Details of the TEM sample preparation have been previously reported. ${ }^{6,24}$ A Cambridge Instruments S-360 microscope was used for SEM analysis of selected samples.

\section{RESULTS}

This work concerns the development of high quality PZT thin films of reproducible properties for ferroelectric memory and micromechanical device applications. Reproducibility requires an understanding of the crystallization mechanisms, and the critical processing variables controlling these. For the preparation of perovskite thin films from organometallic precursors, several variables are known to impact on the crystallization process, as discussed above.

In previous investigations, it was observed that the resulting microstructure and texture of sol-gel prepared thin films could be controlled by changing the pyrolysis temperature while maintaining all other parameters 
invariable. Textures of (111) and (100) were obtained by pyrolyzing at 350 and $420{ }^{\circ} \mathrm{C}$, respectively. ${ }^{6}$ Experiments were therefore initiated in order to understand the mechanisms by which such textures are obtained on identical substrates from identical precursor solutions.

Studies of the thermal stability of the Ti/Pt bilayer metallizations are summarized first, as a preface to the PZT film investigations. Next, XRD and TEM structural analyses of as-pyrolyzed sol-derived films are discussed. These two studies give insight into the structure of the material before perovskite crystallization commences.

The third topic is observations of nucleation and growth of the perovskite phase from the amorphous, as-pyrolyzed material. The kinetics of nucleation and growth were investigated as a function of pyrolysis temperature, choosing two pyrolysis temperatures, 350 and $420{ }^{\circ} \mathrm{C}$, which were known from previous studies to yield different microstructures and textures after rapid thermal annealing at $600{ }^{\circ} \mathrm{C}$. Experiments were designed in order to isolate the nucleation step in both the (111) and (100) textured films. A more detailed look at the effects of pyrolysis temperature on final microstructure follows. The effects of excess $\mathrm{Pb}$ addition are commented upon here.

Based on the pyrolysis temperature results, and previous investigations of sol-gel PZT crystallization as a function of $P_{\mathrm{O}_{2}}$, experiments involving post-pyrolysis thermal treatments in different atmospheres at low temperatures $\left(<450{ }^{\circ} \mathrm{C}\right)$ prior to a final RTA annealing were initiated.

Finally, experiments are presented that were designed to test our ideas concerning microstructural development in PZT films. These include investigations of $\mathrm{PbO}$ films and randomly oriented PZT films.

\section{A. Analysis of $\mathrm{Pt} / \mathrm{Ti}$ electrodes}

Because of the influence of the electrodes on the subsequent crystallization of perovskite PZT as discussed above (Sec. I), experiments were carried out to investigate their stability and orientation. The necessity of a stable electrode system for the study of crystallization processes in PZT thin films must be emphasized. The Pt layer of the as-received substrates was strongly (111) oriented, with no (200) oriented grains detectable by XRD. Thermal stability of the substrate was studied by RTA annealing in $\mathrm{O}_{2}$ at $700{ }^{\circ} \mathrm{C}$ for $60 \mathrm{~min}$. Within the detection limits of $\mathrm{x}$-ray diffraction, no second phases were observed to occur after annealing, and the (111) Pt orientation was retained. Deposition of PZT on annealed and as-deposited electrodes yielded perovskite films of identical orientations and microstructures.

Diffusion and oxidation of $\mathrm{Ti}$ are known to occur in such structures during annealing; however, the Ti adhesion layer is thin $(10 \mathrm{~nm})$ and the volume of $\mathrm{TiO}_{2}$, which can migrate to the surface of the $\mathrm{Pt}$, is consequently small. ${ }^{8}$ Furthermore, the addition of excess $\mathrm{Pb}$ to the precursor solution can compensate for the presence of $\mathrm{TiO}_{2}$ at the Pt surface.

\section{B. Analysis of as-pyrolyzed films}

Figure 1 shows a TEM image of part of a transverse section through an as-pyrolyzed film: pyrolysis temperature $350{ }^{\circ} \mathrm{C}$. The high resolution image reveals a virtually amorphous material, except for some small regions on the order of $5 \mathrm{~nm}$ that appear crystalline. During irradiation by the electron beam, these regions were observed to increase in size. Semiquantitative energy dispersive spectroscopy (EDS) analysis (from TEM) of this sample indicated that the as-pyrolyzed sample was $\mathrm{Pb}$-rich. The as-pyrolyzed film gives rise to two broad rings whose centers lie at " $d$-spacings" of $0.28 \mathrm{~nm}$ and $0.17 \mathrm{~nm}$ (inset of Fig. 1). TEM analysis of films pyrolyzed at 350 and $450{ }^{\circ} \mathrm{C}$ showed similar features in high resolution electron microscopy and electron diffraction. The x-ray diffraction patterns of as-pyrolyzed samples at 350,400 , and $450{ }^{\circ} \mathrm{C}$ were essentially identical, as shown in Fig. 2. In the as-pyrolyzed state, a large diffuse $\mathrm{x}$-ray diffraction peak is observed, centered about $29^{\circ} 2 \theta$. Summarizing, no significant structural differences were observed for films pyrolyzed in the temperature range of 350 to $450{ }^{\circ} \mathrm{C}$.

\section{Observations of nucleation and growth}

Two series of films were prepared by pyrolyzing at either $350{ }^{\circ} \mathrm{C}$ or $420{ }^{\circ} \mathrm{C}$ followed by RTA at $600{ }^{\circ} \mathrm{C}$ for short times and examined using TEM and XRD. The sequence of events that occurs during the crystallization process in these two cases is presented. Previous work had shown that two very different microstructures could be obtained: columnar (111) textured exhibiting small $(\sim 0.1-0.2 \mu \mathrm{m})$ grain sizes at $350{ }^{\circ} \mathrm{C}$ pyrolysis, and (100) textured with large $(\sim 0.5-1.0 \mu \mathrm{m})$ grain sizes at $420^{\circ} \mathrm{C}$ pyrolysis. ${ }^{6}$ Differences in the nucleation and crystallization kinetics were thus investigated.

\section{Pyrolysis at $350{ }^{\circ} \mathrm{C}[(111)$ orientation $]$}

A series of films were prepared by RTA for 1,2 , 5,60 , and $300 \mathrm{~s}$ at $600{ }^{\circ} \mathrm{C}$ (note: for the short duration anneals, the profiles indicated are as programmed and are meant for comparison only). Analysis of the "aspyrolyzed" films was discussed in Sec. III. A. Figure 3 shows a comparison of XRD patterns obtained from films annealed for 1 and $2 \mathrm{~s}$ at $600{ }^{\circ} \mathrm{C}$. The broad amorphous hump centered at $29^{\circ}-2 \theta$ in the as-pyrolyzed film becomes more defined after $1 \mathrm{~s}$ annealing at $600{ }^{\circ} \mathrm{C}$, and then begins to diminish in intensity until it is no longer detectable after $5 \mathrm{~s}$. Even after $1 \mathrm{~s}$, the (111) perovskite peak is observed. As the annealing time is 


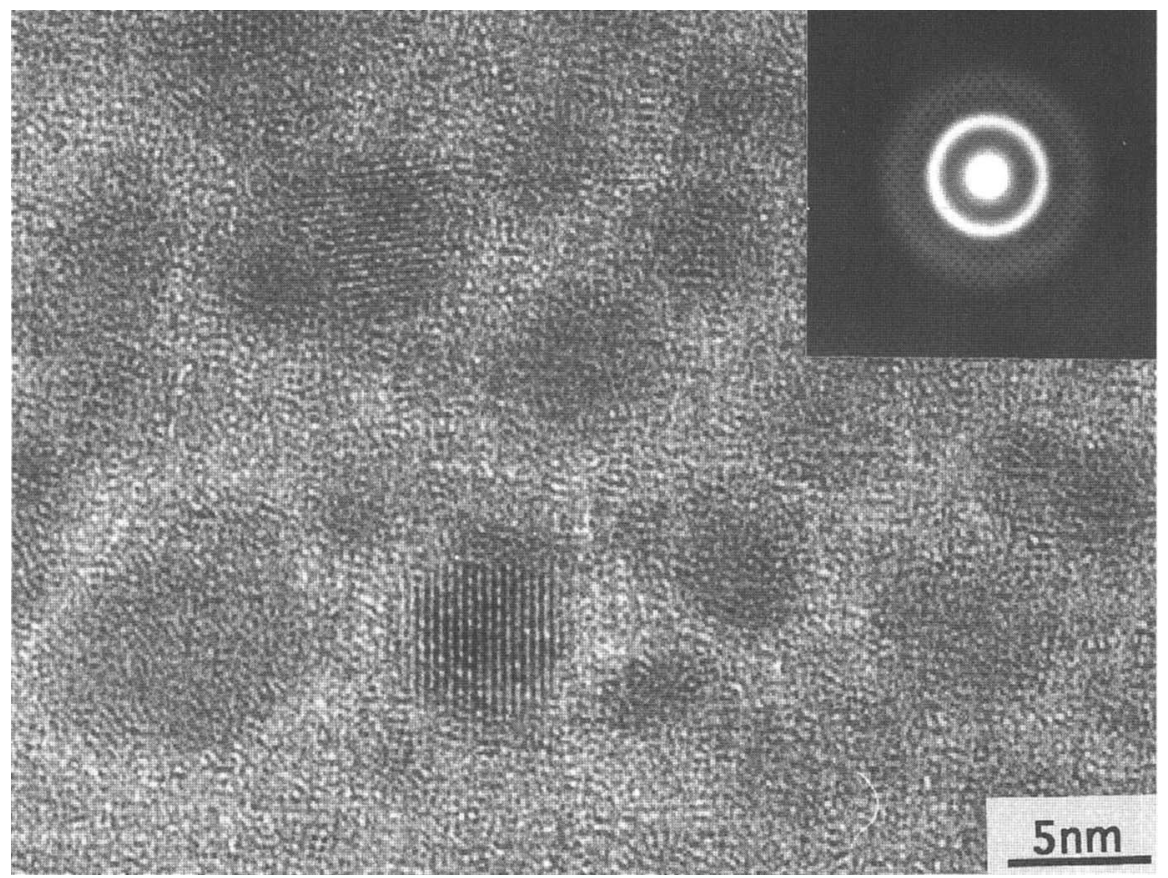

FIG. 1. HRTEM image of an as-pyrolyzed sol-derived film. Pyrolysis temperature was $350{ }^{\circ} \mathrm{C}$; inset shows electron diffraction pattern indicating two diffuse rings.

increased, the (111) perovskite peak rapidly increases in intensity, attaining a maximum at around $60 \mathrm{~s}$. Low intensity (100) and (110) perovskite reflections are also observed to occur in these samples, as shown in Fig. 3 and indicated in Fig. 7 (Sec. III. D).

Transmission electron micrographs of $350{ }^{\circ} \mathrm{C}$ pyrolyzed films annealed at $600{ }^{\circ} \mathrm{C}$ are shown in Figs. 4(a)-4(d). Corresponding electron diffraction images are included as insets in Figs. 4(a) and 4(b). A sample annealed at $600{ }^{\circ} \mathrm{C}$ for $1 \mathrm{~s}$ is shown in the transverse section of Fig. 4(a). Small perovskite nuclei are readily observed at the $\mathrm{Pt} /$ film interface, whereas the bulk of the film consists of a nanocrystalline phase. A

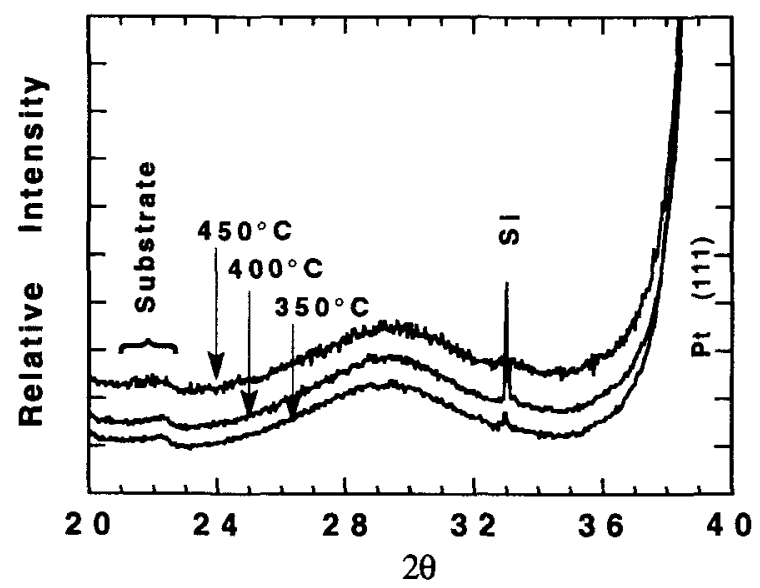

FIG. 2. Comparison of XRD patterns of as-pyrolyzed films at 350 , 400 , and $450{ }^{\circ} \mathrm{C}$. (Note: the broad double peak between 20 and $23^{\circ}$ $2 \theta$ was confirmed to originate from the substrate.) similar image of a film annealed for $2 \mathrm{~s}$, Fig. 4(b), shows that the nuclei have become predominantly columnar, perovskite grains that traverse about half of the film thickness. After $5 \mathrm{~s}$, the film is virtually fully perovskite with some isolated islands of the nanocrystalline phase on the film surface [Fig. 4(c)]. This nanocrystalline phase has been previously identified as a pyrochlore-type phase. ${ }^{6,26}$ After annealing for $300 \mathrm{~s}$, Fig. 4(d), a strongly columnar perovskite microstructure is observed, with a few isolated pyrochlore nanocrystals.

The electron diffraction patterns inserted in Figs. 4(a) and 4(b) show the temporal development of the crystalline phases. The pyrochlore phase [inset

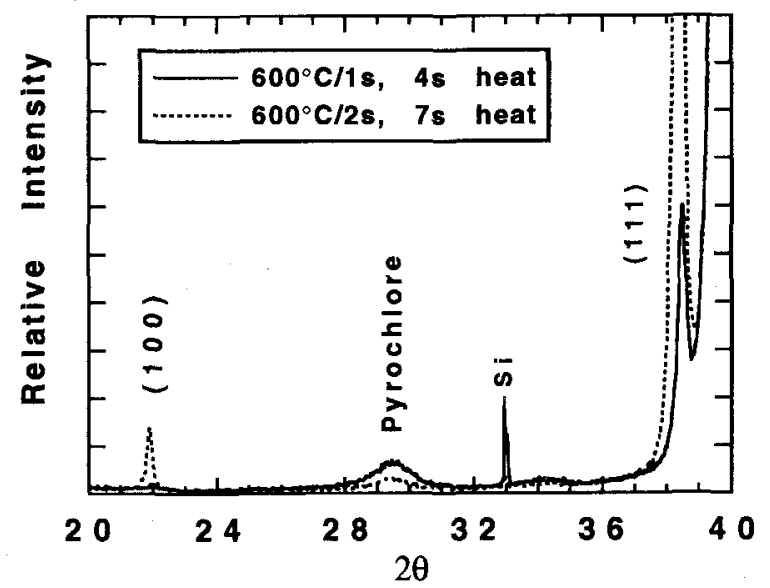

FIG. 3. XRD patterns of $350{ }^{\circ} \mathrm{C}$ pyrolyzed films RTA annealed at $600{ }^{\circ} \mathrm{C}$ for $1 \mathrm{~s}$ and $2 \mathrm{~s}$ using heating rates of $150^{\circ} \mathrm{C} / \mathrm{s}$ and $80{ }^{\circ} \mathrm{C} / \mathrm{s}$, respectively. 

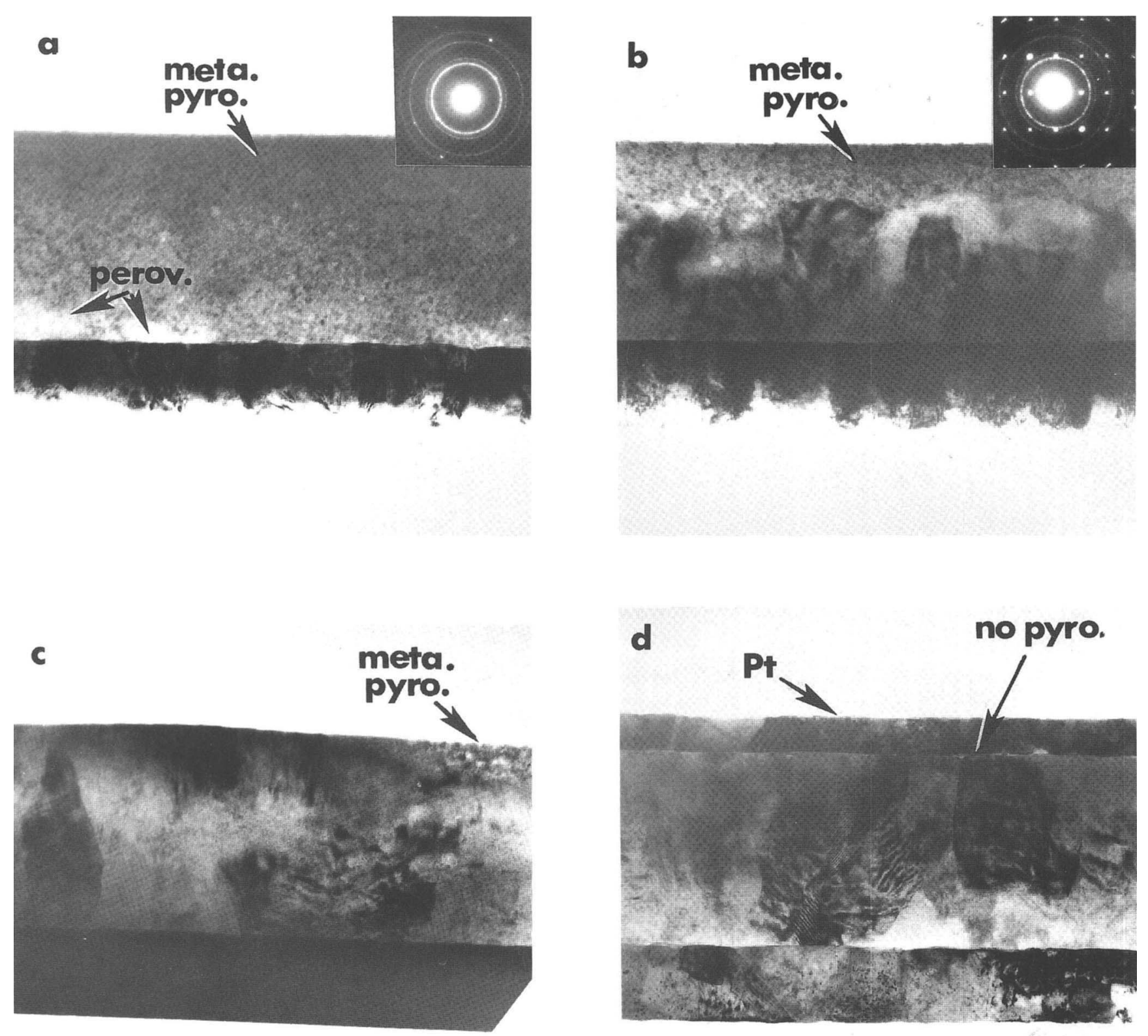

\section{$\underline{\underline{0.1} \mu \mathrm{m}}$}

FIG. 4. TEM transverse section micrographs of $350{ }^{\circ} \mathrm{C}$ pyrolyzed PZT films RTA annealed at $600{ }^{\circ} \mathrm{C}$ for (a) $1 \mathrm{~s}$, (b) $2 \mathrm{~s}$, (c) $5 \mathrm{~s}$, and (d) $300 \mathrm{~s}$. Regions of metastable pyrochlore (meta. pyro.) are indicated. Insets in (a) and (b) are electron diffraction patterns from the respective films (compare with Fig. 3).

Fig. 4(a)], present after $1 \mathrm{~s}$, exhibits two rings that were at approximately the same positions as the broad rings which were observed for the as-pyrolyzed samples (refer to Fig. 1 and Sec. III. B). The scattered reflections originate from the perovskite nuclei. From the complementary XRD patterns, Fig. 3, these nuclei are known to be (111) oriented. The electron diffraction pattern inset in Fig. 4(b) (RTA at $600{ }^{\circ} \mathrm{C}$ for $2 \mathrm{~s}$ ) was taken from a single grain of perovskite and the nanocrystalline phase. The perovskite pattern can be indexed as a $\{110\}$ zone axis and the nanocrystalline pyrochlore gives rise to a ring pattern.

A comparison of the ring pattern obtained from the nanocrystalline phase and an XRD pattern with pyrochlore-type phases reveals the best fit to be $\mathrm{Pb}_{2} \mathrm{Ti}_{2} \mathrm{O}_{6}$ (ref. JCPDS 26-142). This is known to be an oxygen deficient, metastable variant of the more conventional pyrochlore structure. It is believed that $\mathrm{Zr}$ is able 
to substitute for $\mathrm{Ti}$ in the pyrochlore structure and that the real macroscopic formula for this phase is $\mathrm{Pb}_{2}\left(\mathrm{Zr}_{0.53} \mathrm{Ti}_{0.47}\right)_{2} \mathrm{O}_{6}$. In previous studies, a Pb-deficient, $\mathrm{Zr}$-rich (with respect to perovskite stoichiometry) pyrochlore-type phase located at the surface of annealed films deposited from a stoichiometric precursor solution was observed. ${ }^{6}$ Semiquantitative EDS analysis showed that the pyrochlore phase in this case is not $\mathrm{Pb}$ deficient. This is supported by the fact that $\mathrm{Pb}_{2}\left(\mathrm{Zr}_{0.53} \mathrm{Ti}_{0.47}\right)_{2} \mathrm{O}_{6}$ is metastable, rapidly transforming to perovskite.

\section{Pyrolysis at $420^{\circ} \mathrm{C}[(100)$ orientation $]$}

Crystallized films that were pyrolyzed at $420{ }^{\circ} \mathrm{C}$ show a (100) preferred orientation. Figure 5 shows a comparison of XRD patterns obtained from films annealed for 1,2 , and $300 \mathrm{~s}$ at $600{ }^{\circ} \mathrm{C}$. After annealing at $600{ }^{\circ} \mathrm{C}$ for $1 \mathrm{~s}$, only pyrochlore peaks were recorded. The (111) and (100) perovskite reflections are observed with $2 \mathrm{~s}$ annealing, as well as those of the pyrochlore. After $300 \mathrm{~s}$, the sample was strongly $(100)$ oriented, but still contained significant quantities of the pyrochloretype phase.

Results of TEM analysis of the $420{ }^{\circ} \mathrm{C}$ pyrolyzed films are summarized in Fig. 6 . Only the nanocrystalline pyrochlore phase was observed in the film after annealing for $1 \mathrm{~s}$ [Fig. 6(a)]. After $2 \mathrm{~s}$, evidence for the presence of perovskite could be found. Figure 6(b) shows a perovskite grain nucleating on the surface of the Pt. In other regions of the ion-thinned sample, large grains of perovskite could be observed which had grown through most of the film thickness. After $300 \mathrm{~s}$, the film was still not fully perovskite, but consisted of regions of perovskite and pyrochlore.

The above results demonstrate the outline of the crystallization mechanism during annealing of a PZT

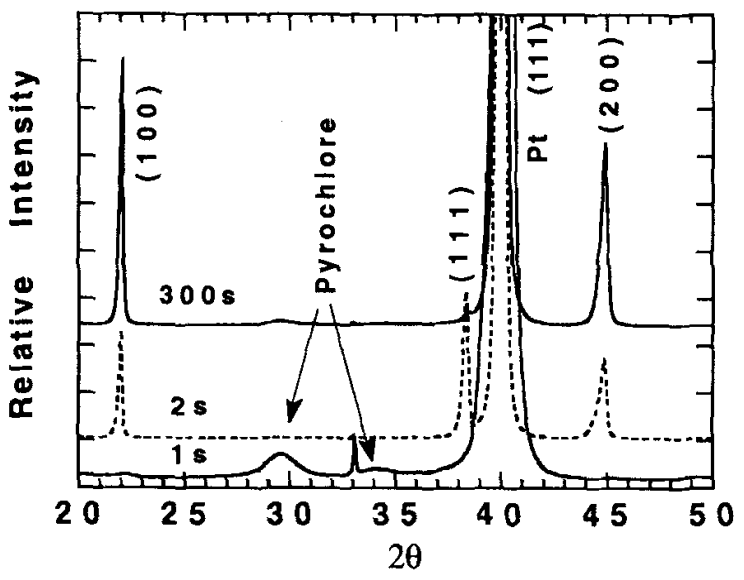

FIG. 5. XRD patterns of $420^{\circ} \mathrm{C}$ pyrolyzed films treated by RTA at $600{ }^{\circ} \mathrm{C}$ for $1 \mathrm{~s}, 2 \mathrm{~s}$, and $300 \mathrm{~s}$, using heating rates of $150{ }^{\circ} \mathrm{C} / \mathrm{s}$, $80^{\circ} \mathrm{C} / \mathrm{s}$, and $80^{\circ} \mathrm{C} / \mathrm{s}$, respectively.

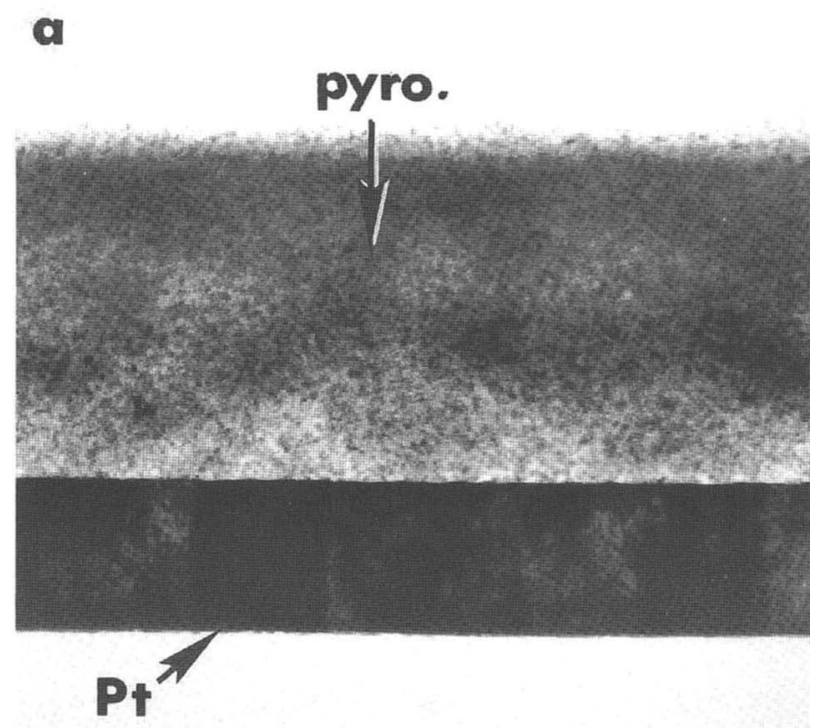

b

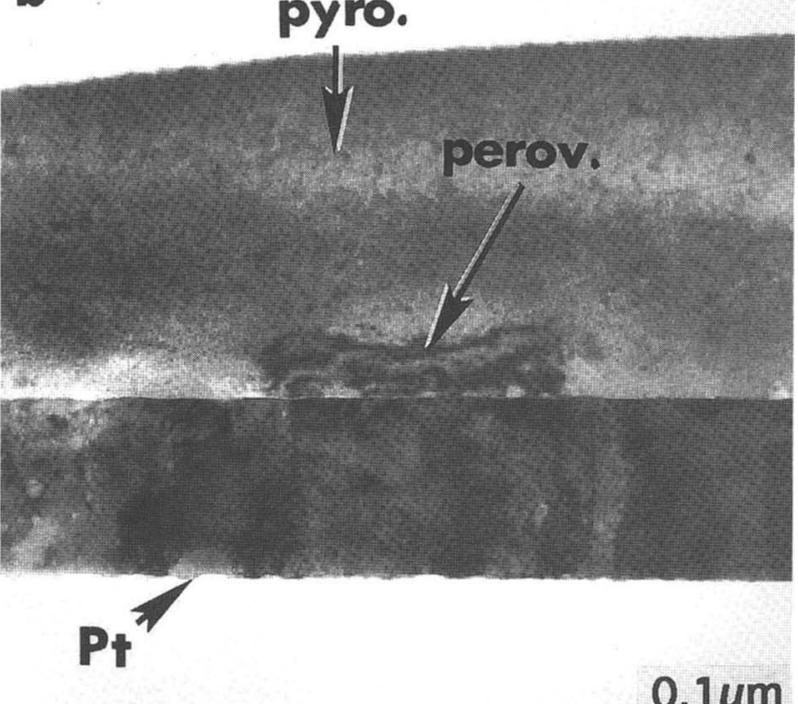

FIG. 6. TEM images of transverse sections of $420{ }^{\circ} \mathrm{C}$ pyrolyzed films RTA annealed for (a) $1 \mathrm{~s}$ and (b) $2 \mathrm{~s}$ (compare with Fig. 5).

film. The amorphous as-pyrolyzed material rapidly transforms to a metastable, pyrochlore structure which in turn transforms to perovskite. The Pt electrode acts as a nucleation site for the perovskite which then grows into the pyrochlore matrix. Comparing the electron diffraction patterns from the as-pyrolyzed material with that from the nanocrystalline phase gives a reasonable match between the $d$-spacings of the pyrochlore structure and the distances between the nearest and next nearest neighbors in the amorphous state. It is perhaps not unreasonable to regard the amorphous phase as a short range ordered 
pyrochlore-structure. In this case, the appearance of a metastable nanocrystalline phase prior to the formation of perovskite will be kinetically favorable.

Aside from the orientation, the most obvious difference between samples pyrolyzed at 350 and $420{ }^{\circ} \mathrm{C}$ is the speed with which the pyrochlore phase is able to transform to perovskite. Comparison of Figs. 5 and 6(a) to Figs. 3 and 4(a) shows that the perovskite phase is not observed in the films annealed for $1 \mathrm{~s}$ at $600{ }^{\circ} \mathrm{C}$ after pyrolysis at $420{ }^{\circ} \mathrm{C}$, but is present for the analogous $350{ }^{\circ} \mathrm{C}$ pyrolyzed film. In addition, the pyrochlore-perovskite transformation does not go to completion even after 5 min at $600{ }^{\circ} \mathrm{C}$ for samples pyrolyzed at $420{ }^{\circ} \mathrm{C}$, but it is virtually complete after $5 \mathrm{~s}$ in the $350{ }^{\circ} \mathrm{C}$ pyrolyzed sample [Fig. 4(c)].

\section{Effect of systematically altering pyrolysis temperature}

Based on the results presented above, a study of the effects of systematically changing the pyrolysis temperature in the range between 350 and $450{ }^{\circ} \mathrm{C}$ at $10{ }^{\circ} \mathrm{C}$ intervals was initiated. The resultant microstructures/textures after annealing at $600{ }^{\circ} \mathrm{C}$ for $300 \mathrm{~s}$ were studied. Two series of films were prepared, containing either $5 \%$ or $10 \%$ excess $\mathrm{Pb}$. Results for the $10 \%$ excess lead containing samples are presented first.

As-pyrolyzed films in the $10 \%$ excess lead containing series were analyzed by XRD and found to be amorphous, exhibiting a single broad hump between approximately 24 and $34^{\circ} 2 \theta$, as demonstrated in Fig. 2 . TEM results, also discussed in the previous section, confirmed that only isolated crystalline particles were present which were no greater than $5 \mathrm{~nm}$ in diameter.

The results from XRD analysis of annealed films are presented graphically in Fig. 7 . In the (pyrolysis) temperature range of 350 to $410{ }^{\circ} \mathrm{C}$, the films exhibit strong (111) texture. The (111) orientation is shown to improve with increasing pyrolysis temperature in the range from 350 to $390{ }^{\circ} \mathrm{C}$. The occurrence of a relatively strong (110) reflection in the temperature range of 350 to $370{ }^{\circ} \mathrm{C}$ is thought to indicate the presence of perovskite grains which have nucleated in the "bulk" of the film (i.e., not at the Pt/PZT interface). In films that had been pyrolyzed at $390{ }^{\circ} \mathrm{C}$, the $(110)$ peak was not observed. For films pyrolyzed at $\leqslant 410{ }^{\circ} \mathrm{C}$, when the (110) reflection is observed, the films still exhibit strong (111) texture, indicating that the nucleation is still dominated by the substrate.

The occurrence of a significant (100) intensity peak begins to appear for a $390{ }^{\circ} \mathrm{C}$ pyrolysis temperature, showing increasing intensity with further increases in (pyrolysis) temperature (Fig. 7). When the pyrolysis temperature reaches $420^{\circ} \mathrm{C}$, an abrupt change from (111) to (100) texture was observed. The occurrence

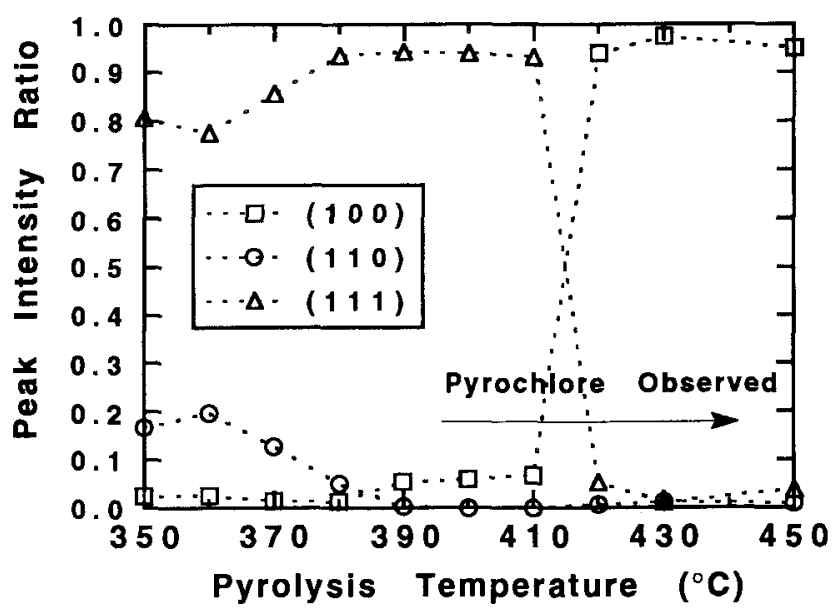

FIG. 7. Graphical representation of XRD results showing orientation as a function of pyrolysis temperature for films RTA annealed at $600{ }^{\circ} \mathrm{C} / 5 \mathrm{~min}$. The peak intensity ratios were calculated according to $(100): I_{(100)} /\left[I_{(100)}+I_{(110)}+I_{(111)}\right] ; \quad(110): I_{(110)} /$ $\left[I_{(100)}+I_{(110)}+I_{(111)}\right] ;$ and $(111): I_{(111)} /\left[I_{(100)}+I_{(110)}+I_{(111)}\right]$.

of pyrochlore in the annealed films was observed by XRD for pyrolysis temperatures $\geqslant 400{ }^{\circ} \mathrm{C}$. The intensity of the (222) pyrochlore peak was found to increase with increasing (pyrolysis) temperature.

TEM images of transverse sections of the films in this series complement the results obtained by XRD. TEM results showed a gradual increase in the columnar nature and lateral grain size of the films as the pyrolysis temperature was increased. This is typified by Fig. 8 , which shows a film pyrolyzed at $380{ }^{\circ} \mathrm{C}$ followed by RTA at $600{ }^{\circ} \mathrm{C}$ for $5 \mathrm{~min}$. Schematic representations of the development of grain size and structure as a function

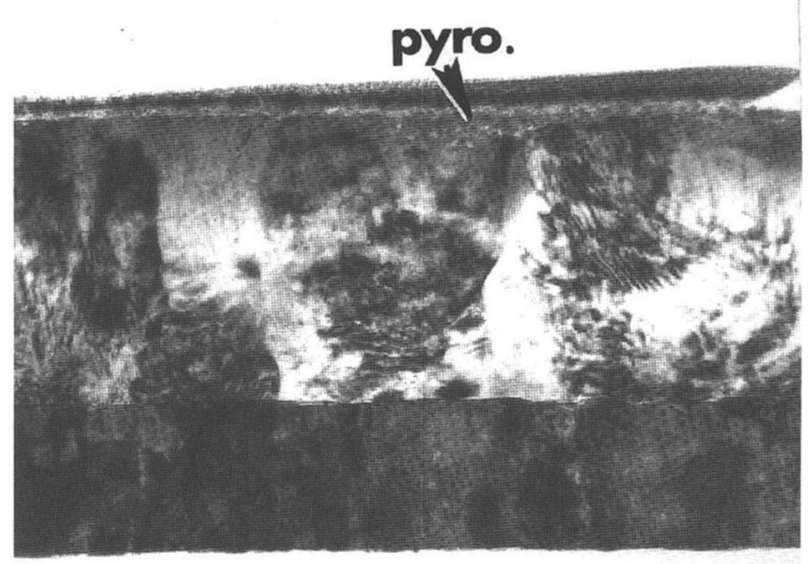

\section{$0.1 \mu \mathrm{m}$}

FIG. 8. TEM image of a transverse section of a PZT film pyrolyzed at $380{ }^{\circ} \mathrm{C}$ and RTA annealed at $600{ }^{\circ} \mathrm{C} / 5 \mathrm{~min}$. 
of increasing pyrolysis temperature are shown in Fig. 9. This is believed to result from a reduction of the growth rate of the perovskite phase, a decrease in the number of nucleation events, and diminution of nucleation in the bulk of the film. This hypothesis is supported by the concomitant decrease of the (110) x-ray peak intensity over this temperature range.

In the pyrolysis temperature interval from 400 to $420{ }^{\circ} \mathrm{C}$, the preferred growth direction was observed to change from (111) to (100) (Fig. 7). In the extreme case, a film annealed at $600{ }^{\circ} \mathrm{C}$ will become stabilized in a two-phase regime and will contain both perovskite and nontransformable pyrochlore. This is illustrated in Fig. 10, which shows an SEM image of the surface of a film prepared using a $430{ }^{\circ} \mathrm{C}$ pyrolysis condition and annealed at $600{ }^{\circ} \mathrm{C}$ for $1 \mathrm{~min}$. The size of the grains (100 oriented) is about 0.5 to $1 \mu \mathrm{m}$, and the dark areas between grains are regions of untransformed pyrochlore. It should be noted that even at $380{ }^{\circ} \mathrm{C}$ pyrolysis, some pyrochlore can be observed at the film surface by TEM (see Fig. 8), although the volume fraction is insufficient to be detected by XRD. For pyrolysis temperatures in excess of $400{ }^{\circ} \mathrm{C}$, essentially pyrochlore free (100) textured films could be obtained only by RTA annealing at $650{ }^{\circ} \mathrm{C}$ and above.

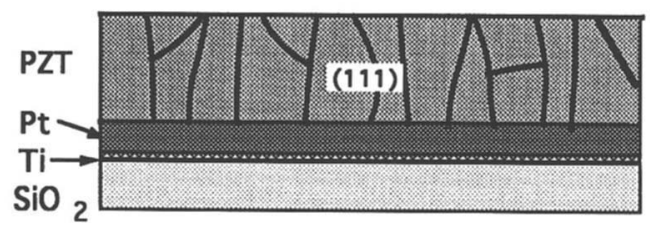

$350^{\circ} \mathrm{C}$

grain size, $\approx 0.1 \mu \mathrm{m}$

(a)

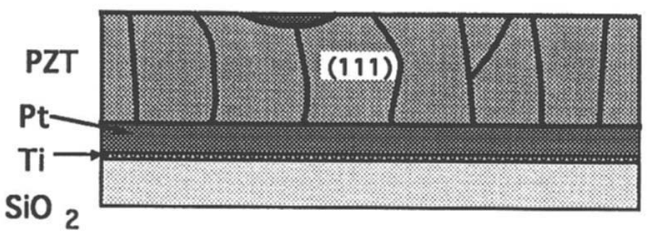

$380^{\circ} \mathrm{C}$

grain size, $\approx 0.2 \mu \mathrm{m}$

(b)

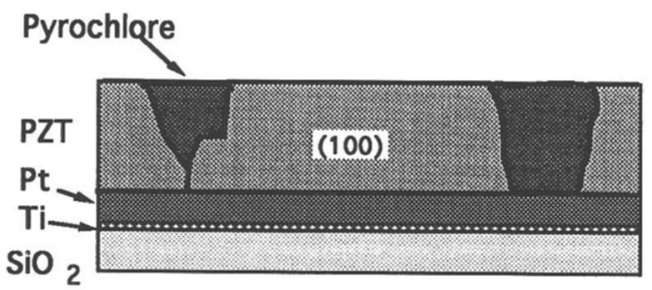

$420^{\circ} \mathrm{C}$

grain size, $\approx 0.5 \mu \mathrm{m}$

FIG. 9. Schematic representations of the changes in grain size and structure which occur as a function of increasing pyrolysis temperature for samples RTA annealed at $600{ }^{\circ} \mathrm{C} / 5 \mathrm{~min}$ : (a) $350{ }^{\circ} \mathrm{C}$ [compare with Fig. 4(d)], (b) $380^{\circ} \mathrm{C}$ (compare Fig. 8), and (c) $420{ }^{\circ} \mathrm{C}$ (compare Fig. 10) pyrolysis temperatures.

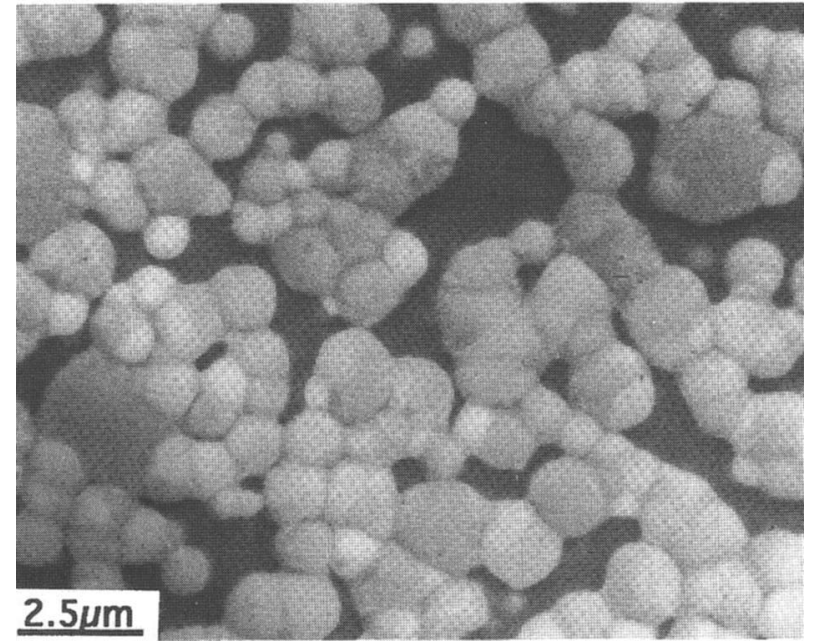

FIG. 10. SEM micrograph of the surface of a (100) textured film prepared by pyrolysis at $430{ }^{\circ} \mathrm{C}$, followed by $600^{\circ} \mathrm{C} / 60$ s RTA.

A second series of experiments similar to those described above was carried out for films containing 5\% excess $\mathrm{PbO}$. The results obtained were almost identical; however, the pyrolysis transition temperature at which the annealed films change from (111) to (100) orientation was shifted downward by approximately 10 to $20^{\circ} \mathrm{C}$. All of the other features described above were found to hold for the case of $5 \%$ excess $\mathrm{Pb}$ samples.

\section{E. Effect of post-pyrolysis thermal treatments}

To understand the effect of pyrolysis temperature on subsequent nucleation/orientation and growth during RTA, experiments were designed in order to ascertain whether pyrolysis at different temperatures affected the oxygen content of the films.

\section{Thermal treatments in reducing atmospheres}

PZT films were prepared by using a $350{ }^{\circ} \mathrm{C}$ pyrolysis condition and either 5 or $10 \%$ excess $\mathrm{Pb}$, and then treated at various temperatures in argon. It was found that a $\mathrm{PbPt}_{x}$ alloy (ref. JCPDS 6-574) formed in the bottom electrode under reducing conditions, and its formation depended on the temperature, strength of the reducing atmosphere, and the quantity of excess $\mathrm{PbO}$ present in the precursor solution. The formation of this phase has previously been reported. ${ }^{1,9}$ One sample which had been prepared with $5 \%$ excess $\mathrm{Pb}$, pyrolyzed at $350{ }^{\circ} \mathrm{C}$, and then RTA annealed in argon at $480{ }^{\circ} \mathrm{C}$ for $300 \mathrm{~s}$ exhibited the presence of the $\mathrm{PbPt}_{x}$ phase by XRD. This film did not show the presence of any perovskite phase. A TEM image of part of a transverse section of this material is shown in Fig. 11. The Pt bottom electrode has been transformed through one third of its thickness into $\mathrm{PbPt}_{x}$ alloy. Longer annealing times under 


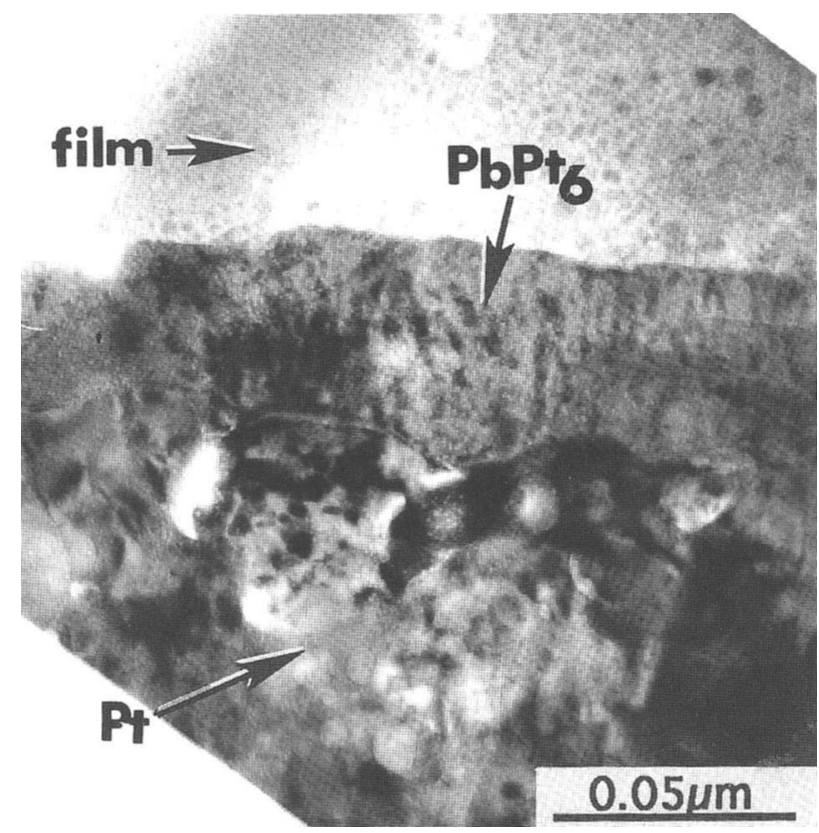

FIG. 11. TEM transverse section of $350^{\circ} \mathrm{C}$ pyrolyzed film annealed in $\mathrm{Ar}, 480^{\circ} \mathrm{C} / 5 \mathrm{~min}$, showing occurrence of $\mathrm{PbPt}_{x}$.

these conditions resulted in complete destruction of the metallization.

Several experiments were carried out in which amorphous as-pyrolyzed films were treated in a forming gas $\left(\mathrm{N}_{2} / \mathrm{H}_{2}: 92 / 8\right)$ atmosphere for various times and temperatures. For a series of films pyrolyzed at $350{ }^{\circ} \mathrm{C}$ and treated in forming gas at temperatures in the range of 300 to $450{ }^{\circ} \mathrm{C}$, only the occurrence of $\mathrm{PbPt}_{x}$ alloy and some residual amorphous material were observed. It was found that the $\mathrm{PbPt}_{x}$ alloy could easily be reoxidized. Figure 12 contains XRD diffraction patterns indicating the presence of $\mathrm{PbPt}_{x}$ after treatment in forming gas at $460{ }^{\circ} \mathrm{C}$ for $2 \mathrm{~min}$ and its subsequent reoxidation after annealing in $\mathrm{O}_{2}$ at $460{ }^{\circ} \mathrm{C}$ for $30 \mathrm{~min}$. After reoxidation, only $\mathrm{Pt}$ and an amorphous phase could be observed by XRD. It should be noted that the occurrence of this alloy was not observed in any of the pyrolyzed or annealed PZT films described above.

\section{Thermal treatments in oxygen}

A series of experiments were designed in order to study the effect of $\mathrm{O}_{2}$ concentration in the amorphous films prior to annealing on the orientation and crystal growth during subsequent RTA. Several illustrative examples are described.

An amorphous film was prepared using a $370{ }^{\circ} \mathrm{C}$ pyrolysis treatment (Sec. III.D), divided into several pieces, and treated in the RTA with pure $\mathrm{O}_{2}$ ambient at $370{ }^{\circ} \mathrm{C}$ for different times. Following these treatments, all of the films were annealed at $600{ }^{\circ} \mathrm{C}$ for $1 \mathrm{~min}$, using the "typical" RTA profile. The thermal treatment times

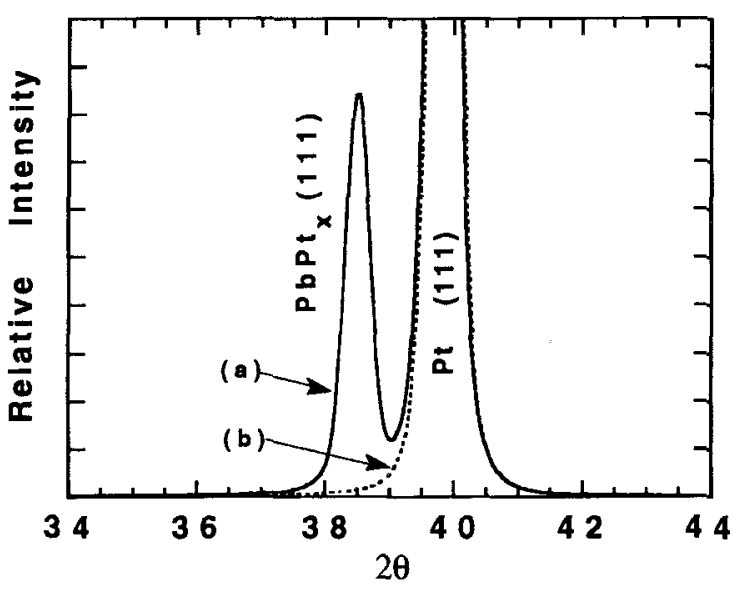

FIG. 12. X-ray diffraction patterns of films pyrolyzed at $350{ }^{\circ} \mathrm{C}$ (a) treated in forming gas atmosphere at $460{ }^{\circ} \mathrm{C} / 2 \mathrm{~min}$, and (b) after subsequent treatment in $\mathrm{O}_{2}$ at $460{ }^{\circ} \mathrm{C} / 30 \mathrm{~min}$, showing the formation of $\mathrm{PbPt}_{x}$ and subsequent reoxidation of the reacted $\mathrm{Pb}$.

included $0,1,5$, and $30 \mathrm{~min}$. Selected $\mathrm{x}$-ray diffraction results are presented in Fig. 13(a). It was observed that the effects of increasing the time of the $\mathrm{O}_{2}$ treatment were analogous to increasing the pyrolysis temperature (Sec. III. D). After the $30 \mathrm{~min}$ treatment in $\mathrm{O}_{2}$ at $370{ }^{\circ} \mathrm{C}$ plus RTA at $600{ }^{\circ} \mathrm{C}$ for $60 \mathrm{~s}$, the XRD pattern is similar to that of a film pyrolyzed at a temperature between 380 and $390{ }^{\circ} \mathrm{C}$ [i.e., the intensities of the $(100)$ and (110) peaks are almost identical, and the film shows very strong (111) texture].

A similar experiment was carried out for $390{ }^{\circ} \mathrm{C}$ pyrolysis, followed by a $30 \mathrm{~min}$ treatment at $390{ }^{\circ} \mathrm{C}$ in $\mathrm{O}_{2}$. In this case, the annealed film without post-pyrolysis treatment showed very strong (111) texture. Annealing after the post-pyrolysis treatment yielded a strong (100) textured film, as shown by comparison in Fig. 13(b).

Similar results were observed for $350{ }^{\circ} \mathrm{C}$ pyrolysis plus $350{ }^{\circ} \mathrm{C}$ post-pyrolysis treatment in $\mathrm{O}_{2}$ that the postpyrolysis treatment in $\mathrm{O}_{2}$ gives an effect similar to an increase in the pyrolysis temperature; i.e., the effective pyrolysis temperature is changed.

\section{Reversible control of oxygen concentration}

To investigate the reversibility of this phenomenon, films were pyrolyzed above the temperature at which the transition occurs from the (111) to the (100) orientation $\left(410{ }^{\circ} \mathrm{C}\right)$ and then subjected to post-pyrolysis treatments in argon. It was found that such films, after standard RTA annealing, would exhibit (111) texture. This is shown in Fig. 13(c), a comparison of the XRD patterns for $\mathrm{Ar}$ treated and nontreated films. The temperature at which the $\mathrm{Ar}$ treatment was carried out was decreased $\left(370{ }^{\circ} \mathrm{C}\right)$ from that of the initial pyrolysis in order to prevent reduction at the film/ $\mathrm{Pt}$ interface, which is known to result in the formation of a $\mathrm{Pb} / \mathrm{Pt}$ alloy (Sec. III. E). 


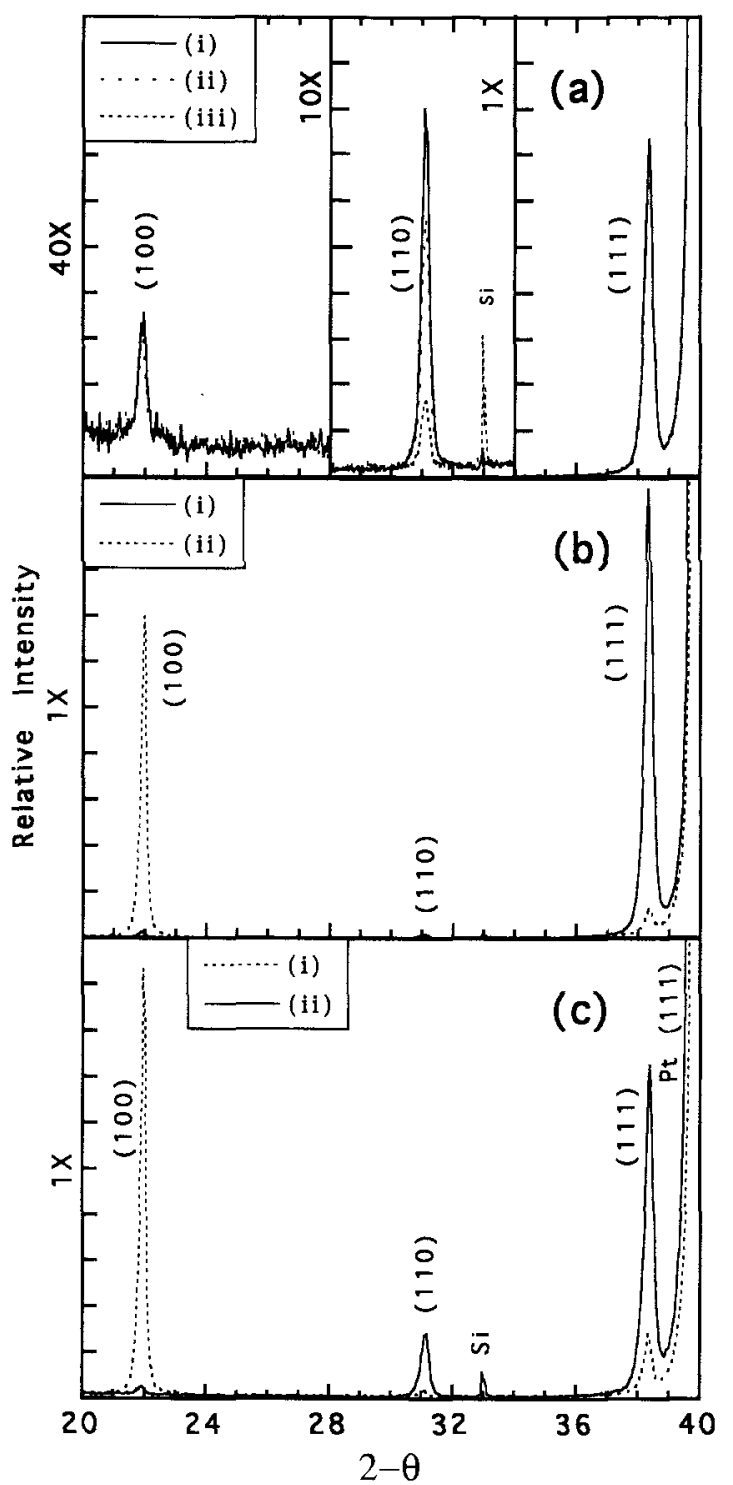

FIG. 13. (a) X-ray diffraction patterns of PZT films pyrolyzed at $370{ }^{\circ} \mathrm{C}$ and (i) RTA at $600{ }^{\circ} \mathrm{C} / 1 \mathrm{~min}$; (ii) treated in $\mathrm{O}_{2}$ at $370{ }^{\circ} \mathrm{C} / 5 \mathrm{~min}$, then $\mathrm{RTA}$ at $600{ }^{\circ} \mathrm{C} / 1 \mathrm{~min}$; and (iii) treated in $\mathrm{O}_{2}$ $370{ }^{\circ} \mathrm{C} / 30 \mathrm{~min}$, then RTA at $600{ }^{\circ} \mathrm{C} / 1 \mathrm{~min}$ (note scale changes at 28 and $34^{\circ} 2 \theta$ ). (b) X-ray diffraction patterns of PZT films pyrolyzed at $390{ }^{\circ} \mathrm{C}$ and (i) RTA annealed at $600{ }^{\circ} \mathrm{C} / 1 \mathrm{~min}$, and (ii) treated at $390{ }^{\circ} \mathrm{C} / 30 \mathrm{~min}$ in $\mathrm{O}_{2}$ followed by $600{ }^{\circ} \mathrm{C} / 1 \mathrm{~min} \mathrm{RTA}$ in air. (c) X-ray diffraction patterns for films pyrolyzed at $420^{\circ} \mathrm{C}$ and (i) RTA annealed at $600{ }^{\circ} \mathrm{C} / 1 \mathrm{~min}$ in air, and (ii) treated in argon at $370{ }^{\circ} \mathrm{C} / 10 \mathrm{~min}$, followed by RTA annealing at $600{ }^{\circ} \mathrm{C}$ in air.

\section{F. Related experiments}

\section{PbO films}

$\mathrm{PbO}_{x}$ films were prepared to investigate their orientation, stoichiometry, and reactions with the Pt substrate material. These films were observed to crystallize directly during the pyrolysis treatment in the investigated temperature range of 300 to $400{ }^{\circ} \mathrm{C}$. The resulting films were highly (001) textured $\mathrm{PbO}$ (litharge), as shown by

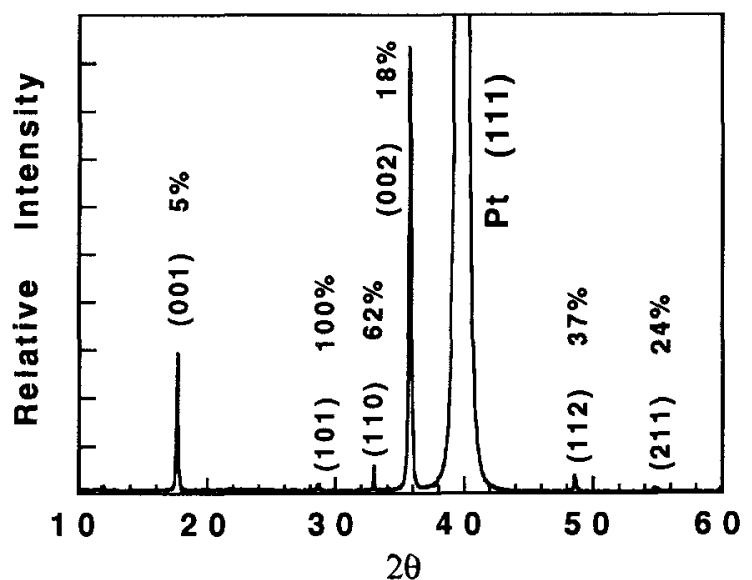

FIG. 14. X-ray diffraction pattern of $\mathrm{PbO}$ (litharge) film prepared by pyrolysis at $300{ }^{\circ} \mathrm{C}$. The percent figures are indicative of the ratios expected for a randomly oriented material (ref. JCPDS No. 5-561).

the XRD pattern of Fig. 14. The (002) lattice spacing of the $\mathrm{PbO}$ structure is $0.2510 \mathrm{~nm}$, which is approximately $10 \%$ larger than the (111) Pt spacing at $0.2265 \mathrm{~nm}$. Similar results were obtained at pyrolysis temperatures of 300,350 , and $400{ }^{\circ} \mathrm{C}$. These results indicate that oriented films with $\mathrm{Pb}-\mathrm{O}$ lattices and lattice mismatches larger than that of (111) perovskite can nucleate on (111) Pt. As an aside, the occurrence of the $\mathrm{PbPt}_{x}$ alloy was not observed in these films. Annealing of a $300{ }^{\circ} \mathrm{C}$ pyrolyzed $\mathrm{PbO}_{x}$ film at $400{ }^{\circ} \mathrm{C}$ for $60 \mathrm{~min}$ in $\mathrm{O}_{2}$ caused the appearance of several low intensity diffraction peaks in addition to the strong $\mathrm{PbO}$ (litharge) peaks. Although a particular $\mathrm{Pb}_{x} \mathrm{O}_{y}$ structure could not be assigned, the occurrence of the peaks can probably be attributed to the formation of $\mathrm{PbO}_{x}$ compounds where $x>1$.

\section{Randomly oriented PZT films}

For the purpose of comparison, randomly oriented PZT films were also prepared. As described above (Sec. II), the technique involved two principal differences in comparison with the highly textured films discussed above: the films were not completely pyrolyzed prior to annealing, and the sol-gel materials were prehydrolyzed. Figure 15 shows a typical XRD pattern for one of the randomly oriented films annealed at $600{ }^{\circ} \mathrm{C}$ for $60 \mathrm{~s}$. It was also observed that randomly oriented films formed when the orientation of the $\mathrm{Pt}$ substrate was not perfect.

\section{DISCUSSION AND OBSERVATIONS}

Based on these results and literature that pertains to this topic, we have developed a descriptive model to explain the origin of the different microstructures observed. Three characteristic microstructures are considered: columnar (111) oriented, columnar (100) 




FIG. 15. X-ray diffraction pattern of a randomly oriented PZT thin film treated by RTA at $600^{\circ} \mathrm{C} / 30 \mathrm{~s}$.

oriented, and polycrystalline randomly oriented. It has been previously reported, ${ }^{25}$ and observed again in this work, that the crystallization of perovskite from a preexisting amorphous film occurs via the following path: amorphous $>$ pyrochlore $>$ perovskite. The processes of nucleation and growth of the perovskite grains from the nanocrystalline pyrochlore matrix therefore will affect the resultant microstructure.

Taking the case of the columnar (111) oriented microstructure, the following scenario was observed. During rapid thermal annealing, the entire amorphous film transforms to a metastable nanocrystalline pyrochlore. Nuclei of (111) orientation form at the film/ substrate $(\mathrm{Pt})$ interface and rapidly grow through the thickness of the film. These observations imply that the (111) nuclei have the lowest interfacial energy with the "substrate" in comparison to other possible nuclei, e.g., (100). Secondly, the observed rapid growth requires that the pyrochlore matrix be metastable so it can be easily transformed to perovskite.

For the case of the (100) oriented films, a similar process was seen to occur with the following important differences. First, it was observed that initially both (100) and (111) perovskite "nuclei" form at the film/substrate interface. Second, the kinetics of both nucleation and growth were observed to be substantially slower than in the case of the (111) oriented films. Third, the lateral size of the (100) nuclei and the resultant lateral grain size of the crystallized film were significantly larger than in the (111) case. Finally, the occurrence of residual pyrochlore was generally observed for the (100) case when annealing conditions identical to those used to obtain the (111) textured films were employed. The following conclusions concerning (100) oriented film formation can thus be made. The mechanism responsible for (111) nucleation is also present in the case of the (100) textured films. Under the conditions used to prepare (100) oriented films, the (100) nuclei are more stable than the (111) nuclei (i.e., they have a lower interfacial energy with the nanocrystalline pyrochlore). The pyrochlore phase present in this case is more difficult to transform to perovskite than in the (111) case.

For the case of randomly oriented films, a detailed investigation of the microstructure development was not undertaken. However, from the resultant polycrystalline microstructure, it is clear that at least some nuclei formed in the bulk of the film. This indicates that even if nucleation commenced at the film/substrate interface, inhomogeneities in the structure prevented continued growth through the film thickness.

From these scenarios, the following questions arise: (i) What is the mechanism(s) by which nuclei of either (111) or (100) orientation form at the film/substrate interface? (ii) What factors control the kinetics of the pyrochlore to perovskite transformation? and (iii) What processing differences could lead to the inhomogeneities which result in randomly oriented films?

A discussion of the experimental observations and the implications of these observations in terms of developing answers to the questions posed above follows. Possible nucleation mechanisms are discussed first.

Understanding the mechanisms by which nuclei of various orientations form at the film/substrate interface is quite complex. Although an unequivocal explanation cannot be given at this time, evidence derived from the experimental work presented here can be used to narrow the possibilities. First, we consider previously published explanations in light of our results.

In the literature, the two following mechanisms have been proposed for the nucleation of (111) PZT on (111) oriented Pt substrates. The most often reported is the direct nucleation of PZT on Pt due to lattice matching between (111) Pt and (111) PZT. 2,7 The second proposed mechanism is that a transient $\mathrm{PbPt}_{x}$ alloy forms at the interface (due to reduction of $\mathrm{Pb}$ and reaction with $\mathrm{Pt}$ ) and (111) PZT nucleates on this cubic phase due to the almost identical (111) lattice parameters of the two phases. ${ }^{9}$ It has also been reported that preannealing of the Ti/Pt bilayer metallization prior to PZT deposition can affect the orientation of the PZT.

Our results tend to support the first of these mechanisms. The nucleation of (111) oriented crystallites at the film/substrate interface and subsequent growth of said through the thickness of the films was observed directly by TEM. The experiments with $\mathrm{PbO}$ films also indicate that lattices with even greater mismatch (tetragonal $\mathrm{PbO}$ ) can nucleate on the (111) Pt to form highly textured films, as discussed in Sec. III. D. Other observations presented above have led to the following more detailed explanation of the direct nucleation mechanism.

The diffusion of Ti species through the Pt from the underlying Ti adhesion layer is known to occur at the 
processing temperatures employed for the preparation of PZT films. ${ }^{7,8}$ The oxidation of such Ti species at the film Pt interface during thermal processing of the PZT could lower the interfacial energy between the (111) nuclei which form on the (111) Pt in the following way. We propose that the presence of $\mathrm{TiO}_{x}$ at the growth interface could facilitate nucleation of titania-rich (111) PZT perovskite due to a reduction of the lattice mismatch between Pt and the perovskite. Pure $\mathrm{PtTiO}_{3}$ has a much smaller (111) lattice mismatch (less than 1.5\%) with (111) Pt than the morphotropic phase boundary composition $(3.6 \%)$. In other investigations, we have observed that PZT films prepared by the techniques described above (i.e., $350{ }^{\circ} \mathrm{C}$ pyrolysis and $600{ }^{\circ} \mathrm{C}$ RTA annealing) on strongly (111) oriented Pt electrodes with a Ta adhesion layer were randomly oriented and columnar. The introduction of a thin layer of $\mathrm{TiO}_{x}$ at the film/ $\mathrm{Pt}$ interface, prior to PZT deposition, however, yielded films of strong (111) orientation. These results further support the hypothesis that $\mathrm{Ti}$ diffusion contributes to the nucleation of (111) PZT on (111) Pt. ${ }^{26}$

The mechanism whereby (111) perovskite nucleation is favored due to the formation of a metastable $\mathrm{PbPt}_{x}$ alloy is similar in that it involves a means by which the lattice mismatch between substrate and film is reduced. In this case, however, the metallization is altered to increase its lattice parameter such as to be almost identical to that of the morphotropic composition perovskite $(\sim 0.5 \%$ difference $) .{ }^{9}$ However, several observations discussed above would tend to preclude this as a necessity for (111) growth. First, $\mathrm{PbPt}_{x}$ was not observed by TEM at the interface in any of the as-pyrolyzed films investigated. Second, in films post-pyrolysis treated in $\mathrm{O}_{2}$ for long periods of time, the (111) phase can be obtained. This is a significant result because in another experiment, it was shown that once formed, the $\mathrm{PbPt}_{x}$ alloy can readily be reoxidized (Sec. III.E). Finally, if the metastable $\mathrm{PbPt}_{x}$ alloy does not exist prior to RTA annealing in air, it would seem difficult to imagine a mechanism that would cause reduction of the $\mathrm{Pb}$ to form such an alloy.

Substrate preannealing has also been reported to have a profound influence on the orientation of the PZT obtained due to the formation of Pt hillocks of assumed (100) orientation. ${ }^{7}$ Our results indicate that if the asdeposited $\mathrm{Pt}$ is stable (i.e., the degree of orientation does not change when subjected to annealing at $700{ }^{\circ} \mathrm{C}$ in the absence of PZT), then the formation of Pt hillocks does not occur. We have observed by XRD that after a 60 min anneal of the substrate at $700{ }^{\circ} \mathrm{C}$ in $\mathrm{O}_{2}$, the (111) Pt orientation was not affected, and in fact no (200) oriented grains could be observed. In all of the TEM investigations carried out for this study, Pt hillocks were never observed. It also is reasonable to argue that the reversible control of the PZT orientation by post- pyrolysis heat treatments (Sec. III. E) precludes the idea that $\mathrm{Pt}$ recrystallization is the controlling factor for orientation differences in our films. The fact that identical PZT microstructures/orientations were obtained on asdeposited and preannealed electrodes further supports this premise.

In the literature, the formation of (100) oriented films on predominantly (111) oriented Pt has generally been ascribed to the fact that (100) is the energetically favored growth direction. ${ }^{7,9}$ In the absence of a mechanism for nucleation and rapid growth of (111) oriented perovskite (such as that described above), the argument of low interfacial energy of the (100) planes would suggest that (100) growth is preferred. Assuming this to be the case, it remains to determine the mechanism by which the growth of (111) nuclei is suppressed.

This leads us into the second question posed above, that of the pyrochlore to perovskite transformation kinetics. The stability of the transient pyrochlore phase which forms was observed to depend on the pyrolysis temperature and the post-pyrolysis treatments in oxygen, this based on the quantity of residual pyrochlore remaining after RTA annealing, and the temperature required to transform all of the pyrochlore to perovskite. The post-pyrolysis experiments suggest that the stability is linked in some way to the relative oxygen concentration in the films. Assuming for the moment that longer treatments in $\mathrm{O}_{2}$ lead to higher oxygen concentrations in the film prior to annealing, we hypothesize the following. If the oxygen concentration is "less", then the transient pyrochlore phase that forms will be metastable, and assumes the formula: $\mathrm{Pb}_{2}(\mathrm{Ti}, \mathrm{Zr})_{2} \mathrm{O}_{6}$. Due to the metastability and the stoichiometry being nearly identical to perovskite, the kinetics of the pyrochlore to perovskite transformation should be enhanced. For the case of "greater" oxygen concentrations, the more stable pyrochlore, $\mathrm{Pb}_{2}(\mathrm{Ti}, \mathrm{Zr})_{2} \mathrm{O}_{7-x},{ }^{27}$ forms, thus slowing the pyrochlore to perovskite transformation. The difference between these two pyrochlore structures is related to the valence state of $\mathrm{Pb}$ in the structure. In the former case, for electroneutrality, all of the lead must be $2^{+}$. The second case allows for some quantity of $\mathrm{Pb}^{4+}$, if $x<1$. The fact that similar results were obtained by either increasing the pyrolysis temperature or increasing the time of a given post-pyrolysis treatment in oxygen suggests that the relative oxygen content increases with increasing pyrolysis temperature over the temperature range investigated.

Fox et al. reported that the lead valence state has a strong influence on the degree to which the pyrochlore to perovskite transformation goes to completion in multiion-beam reactive sputtered PLT thin films. Pyrochlore stability was found to increase with increasing oxygen content. It was also shown that this transformation is enhanced by increasing time and temperature. ${ }^{5}$ Our 
experiments for films treated in $\mathrm{O}_{2}$ atmospheres at low temperature prior to RTA annealing yield similar results (Sec. III.E). For constant RTA profiles, the quantity of residual pyrochlore was always significant in the films treated in $\mathrm{O}_{2}$ atmospheres for prolonged times. We also observed that in such films, the pyrochlore phase can essentially be eliminated if the annealing temperature is increased from 600 to $650{ }^{\circ} \mathrm{C}$. Hirano et al. reported that (111) textured films could be prepared on (111) $\mathrm{Pt}$ substrates by treating the films in a mixture of $\mathrm{H}_{2} \mathrm{O} / \mathrm{O}_{2}$ at $350{ }^{\circ} \mathrm{C}$ prior to annealing, whereas treatments in pure $\mathrm{O}_{2}$ yielded only pyrochlore in the annealed films. ${ }^{2}$ This work indicates the impact of oxidizing/reducing treatments prior to annealing; however, a more detailed comparison is not possible due to differences in the precursor systems and annealing conditions employed.

The work of Sorrel on the isothermal oxidation of $\mathrm{PbO}$ in air over the temperature range of 286 to $350{ }^{\circ} \mathrm{C}$ lends further support to our arguments. ${ }^{26} \mathrm{It}$ was observed that the oxidation state of $\mathrm{Pb}$ is very sensitive to change in the aforementioned temperature regime, and that several different $\mathrm{Pb}_{x} \mathrm{O}_{y}$ structures can be formed. This temperature range just meets the lower end of the pyrolysis temperature range employed in this study. The equilibrium $\mathrm{PbO}_{x}$ stoichiometry obtained for $\mathrm{PbO}$ annealed at these temperatures varied from $x=1.33$ to 1.55 , indicating the presence of a significant level of $\mathrm{Pb}^{+4}$ ions. ${ }^{26}$ The occurrence of $\mathrm{Pb}^{+4}$ ions in amorphous PZT films would, reasonably, tend to favor the formation of the more stable pyrochlore $\mathrm{Pb}_{2}\left(\mathrm{Zr}_{0.53} \mathrm{Ti}_{0.47}\right)_{2} \mathrm{O}_{7-x}$ in deference to the metastable variant $\mathrm{Pb}_{2}\left(\mathrm{Zr}_{0.53} \mathrm{Ti}_{0.47}\right)_{2} \mathrm{O}_{6}$. Although our results for $\mathrm{PbO}_{x}$ are not entirely conclusive, there is some evidence that changes in the oxidation state of $\mathrm{Pb}$ does occur during annealing in $\mathrm{O}_{2}$ at $400{ }^{\circ} \mathrm{C}$.

The experimental results presented above provide compelling evidence that oxygen concentration or more specifically lead valence state in amorphous films prior to rapid annealing plays a critical role in determining the kinetics of nucleation and growth of perovskite PZT. Control of the lead valence state effectively allows for preparation of PZT films of controlled, reproducible microstructures and textures with essentially no residual pyrochlore.

Some other secondary observations are worth noting. The effect of residual carbon on the crystallization process has not been determined, but as a result of the above described experiments and particularly the reversibility (Sec. III.E), we believe that it is not a significant factor for the precursor systems and processing treatments described above. If residual carbon were a principal factor, then the reversibility of the process would not hold. The crystallization of the $\mathrm{PbO}$ films during $300{ }^{\circ} \mathrm{C}$ pyrolysis further supports this argument.

The final question concerns the origin of randomly oriented polycrystalline microstructures. This type of microstructure has been reported extensively in the literature for both physical and chemical preparation methods. The occurrence of such a structure is indicated when the film prior to annealing is not homogeneous on a nanoscale. Many types of defects (e.g., porosity, residual organics, etc.) could act as nucleation sites for crystallization of perovskite in the "bulk" of the film or act to prevent the growth of oriented grains through the film thickness. The processing parameters of the randomly oriented films described above were purposely altered in such a way as to create such defects. Prehydrolysis seems to be one important factor for obtaining random structures. Random orientation can also occur if the substrate does not provide for the nucleation of oriented grains, either due to poor quality diffusion between the film and the substrate or lattice incompatibility between film and substrate. The preparation of PZT films on (0001) oriented $\mathrm{Al}_{2} \mathrm{O}_{3}$ substrates by sol-gel, via a processing scheme analogous to that described above for the (111) textured films on Pt yielded films of random orientation. ${ }^{28}$ Similar results were reported by Hirano et al. ${ }^{2}$

\section{CONCLUSIONS}

It has been shown that PZT films of controlled microstructure ranging from randomly oriented fine grained $(\sim 0.1 \mu \mathrm{m})$ polycrystalline structures to highly columnar (111), $(100)$, or mixed $(111)+(100)$ textures can be reproducibly prepared on stable (111) oriented Pt substrates by sol-gel processing combined with rapid thermal annealing. Pyrolysis temperature and postpyrolysis treatments in oxygen were determined to be the critical parameters for controlling the nucleation, growth, and final microstructure of the films. Pyrolysis in the regime of 350 to $410{ }^{\circ} \mathrm{C}$ was observed to yield (111) textured films upon annealing and in the regime of 420 to $450{ }^{\circ} \mathrm{C}$ to yield (100) textured films. Postpyrolysis treatments in oxygen were generally observed to favor the (100) oriented growth. A mechanism for (111) oriented perovskite growth on (111) Pt based on titania-rich perovskite nuclei which have a closer lattice match to the $\mathrm{Pt}$ than the morphotropic boundary composition was proposed. Diffusion of $\mathrm{Ti}$ from the adhesion layer through the $\mathrm{Pt}$ was the source of the enhanced $\mathrm{Ti}$ concentration at the growth interface. It is argued that the stability of the transient pyrochlore which forms prior to perovskite crystallization influences the kinetics of the transformation and thus the resultant microstructure. Further, oxygen concentrations prior to annealing are suggested as a source of differences in the stability of the transient pyrochlore phase.

\section{ACKNOWLEDGMENTS}

This work was supported by the Swiss Federal Office for Science and Education (OFES), by the Swiss 
Commission for the Encouragement of Scientific Research (CERS) through the $\mathrm{M}^{2} \mathrm{~S}^{2}$ program, the European ESPRIT program FELMAS, and by the Swiss Priority Program, LESIT.

\section{REFERENCES}

1. M. Klee, A. De Veirman, P. Van de Weijer, U. Mackens, and H. Van Hal, Philips Res. Rep. 47, 263 (1993).

2. S. Hirano, T. Yugo, K. Kikuta, Y. Araki, M. Saitoh, and S. Ogasahara, J. Am. Ceram. Soc. 75 (10), 2785 (1992).

3. G. J. M. Dormans, M. de Keijser, P. J. van Veldhoven, D. M. Frigo, J. E. Holewijn, G.P. M. van Mier, and C. J. Smit, Chem. Mater. 5, 448 (1993).

4. R. Braukhaus, H. Huber, D. Pitzer, and W. Wersing, Ferroelectrics 127, 137 (1992).

5. G. R. Fox and S. B. Krupanidhi, J. Mater. Res. 9, 699 (1994).

6. I. M. Reaney, K. G. Brooks, R. Klissurska, Cz. Pawlaczyk, and N. Setter, J. Am. Ceram. Soc. 77, 1209 (1994).

7. G. A. C. M. Spierings, J. B. A. van Zon, M. Klee, and P. K. Larsen, Proc. 4th Int. Symp. on Integrated Ferroelectrics, Monterey, CA, March 9-11, 1992.

8. K. Sreenivas, I. Reaney, T. Maeder, N. Setter, C. Jagadish, and R. G. Elliman, J. Appl. Phys. 75 (1), 232 (1994).

9. S. Chen and I. Chen, IMF Proc., August (1993).

10. V. Chikarmane, C. Sudhama, J. Kim, J. Lee, and A. Tasch, Appl. Phys. Lett. 59 (22), 2850 (1991).

11. G. A.C.M. Spierings, M.J.E. Ulenaers, G. L.M. Kampschoer, H. A. M. van Hal, and P. K. Larsen, J. Appl. Phys. 70 (4), 2290 (1991).

12. D. F. Ryder, Jr. and N. K. Raman, J. Elec. Mater. 21 (10), 971 (1992).
13. G. R. Fox, S. B. Krupanidhi, K. L. More, and L.F. Allard, J. Mater. Res. 7, 3039 (1992).

14. E. M. Griswold, M. Sayer, and D. T. Amm, Can. J. Phys. 69, 260 (1991).

15. B. A. Tuttle, D. H. Doughty, R. W. Schwartz, T.J. Garino, S. L. Martinez, R.G. Tissot, and W.F. Hammetter, Ceram. Trans. (Mater. Processes Microelectron Syst.) 15, 179-191 (1990).

16. M. Huffman and P. J. Schuele, Ferroelectrics 143, 251 (1993).

17. M. Klee and P. Larsen, Ferroelectrics 133, 91 (1992).

18. R. A. Lipeles, D. J. Coleman, and M.S. Leung, IEEE Trans. Ultrasonics, Ferroelectrics, and Frequency Control 38 (6), 684 (1991).

19. N. Tohge, S. Takahashi, and T. Minami, J. Am. Ceram. Soc. 74 (1), 67 (1991).

20. T.W. Dekleva, J. M. Hayes, L. E. Cross, and G. L. Geoffrey, J. Am. Ceram. Soc. 71 (5), C280 (1988).

21. R. A. Lipeles, D. J. Coleman, and M. S. Leung, in Better Ceramics through Chemistry II, edited by C. J. Brinker, D. E. Clark, and D. R. Ulrich (Mater. Res. Soc. Symp. Proc. 73, Pittsburgh, PA, 1986), p. 665.

22. L. Bursill and K. Brooks, J. Appl. Phys. (1994, in press).

23. K. D. Budd, S. K. Dey, and D. A. Paine, Brit. Ceram. Proc. 36, 107 (1985).

24. I. M. Reaney, D. J. Barber, and R. Watton, J. Mater. Sci.: Mater. Electron. 3, 51 (1992).

25. B. A. Tuttle, R. W. Schwartz, D. H. Doughty, and J. A. Voigt, in Ferroelectric Thin Films, edited by E. R. Meyers and A. I. Kingon (Mater. Res. Soc. Symp. Proc. 200, Pittsburgh, PA, 1990), p. 159.

26. C. Sorrell, J. Am. Ceram. Soc. 56 (12), 613 (1973).

27. H. Magaw, Ferroelectricity in Crystals (Methuan \& Co., Ltd., London, 1957).

28. K. Brooks, T. Maeder, and I. Reaney, unpublished research. 